\title{
A NEW FLEXIBLE SPRING-COIL, MULTI-DIRECTIONAL MOUNTING DEVICE (WITH PROPOSAL OF RULES) FOR TARGET SHOOTING BY THE DISABLED
}

\author{
By Abraham Ohry, M.D. ${ }^{1}$ and Elhanan TalmoR ${ }^{2}$ \\ 1 The Sir Ludwig Guttmann Spinal Cord Injury Center, Ch. Sheba Medical Center, Tel- \\ Hashomer, and ${ }^{2}$ Zahal Disabled Veterans Organisation, Beit-Halochem Sports, Rehabilitation \\ and Social Center, Afeka, Tel Aviv, Israel
}

\begin{abstract}
A new device which helps the tetraplegic patient participate in target
\end{abstract} shooting is described. We also propose rules for target shooting by the disabled.

Key words: Sport; Rifle; Mechanical aids; Rules.

\section{Introduction}

TARGET SHOOTING is very popular in Israel among the disabled. The sport includes rifle and pistol shooting at different distances, in various firing positions and with different calibres. This sport is a challenge to every severely injured patient of any age. Using different kinds of firing rates may encourage wheelchairbound persons to compete with healthy people. With the development of new techniques in this field, we present a new flexible spring-coil multi-directional rifle mount device which enables severe upper extremity handicapped people to move and aim the rifle more easily. We will also suggest our proposal of rates and regulations for target shooting by the disabled.

\section{The Device}

The picture shows a tetraparetic patient sitting in his chair with the rifle at a comfortable height. The spring allows the patient to aim the gun in the desired directions. Both hands are free for this. The rifle butt is on the shoulder. The right hand clutches the stock and the left hand (or even the right) is ready to pull the trigger. This spring allows a severely handicapped patient more independent activity in this sport, thus achieving greater satisfaction in participation and better results.

\section{Our Proposal for New Rules}

When appraising the physical fitness required for target shooting in a standing position, several factors should be considered: (I) the strength and activity of the muscles involved; and (2) the presence of superficial and deep sensation in the lower extremities. This proprioceptive sensation enables a person in a standing position (particularly while target shooting) to activate the proper muscles, thereby correcting even the slightest deviation from the optimal position required.

When one or both of these physical abilities are missing, some compensation has to be allowed for. People with spinal cord injury lacking motor and sensory

Address for offprints: A. Ohry, M.D., Rehabilitation Center, Ch. Sheba Medical Center, Tel-Hashomer, Israel. 

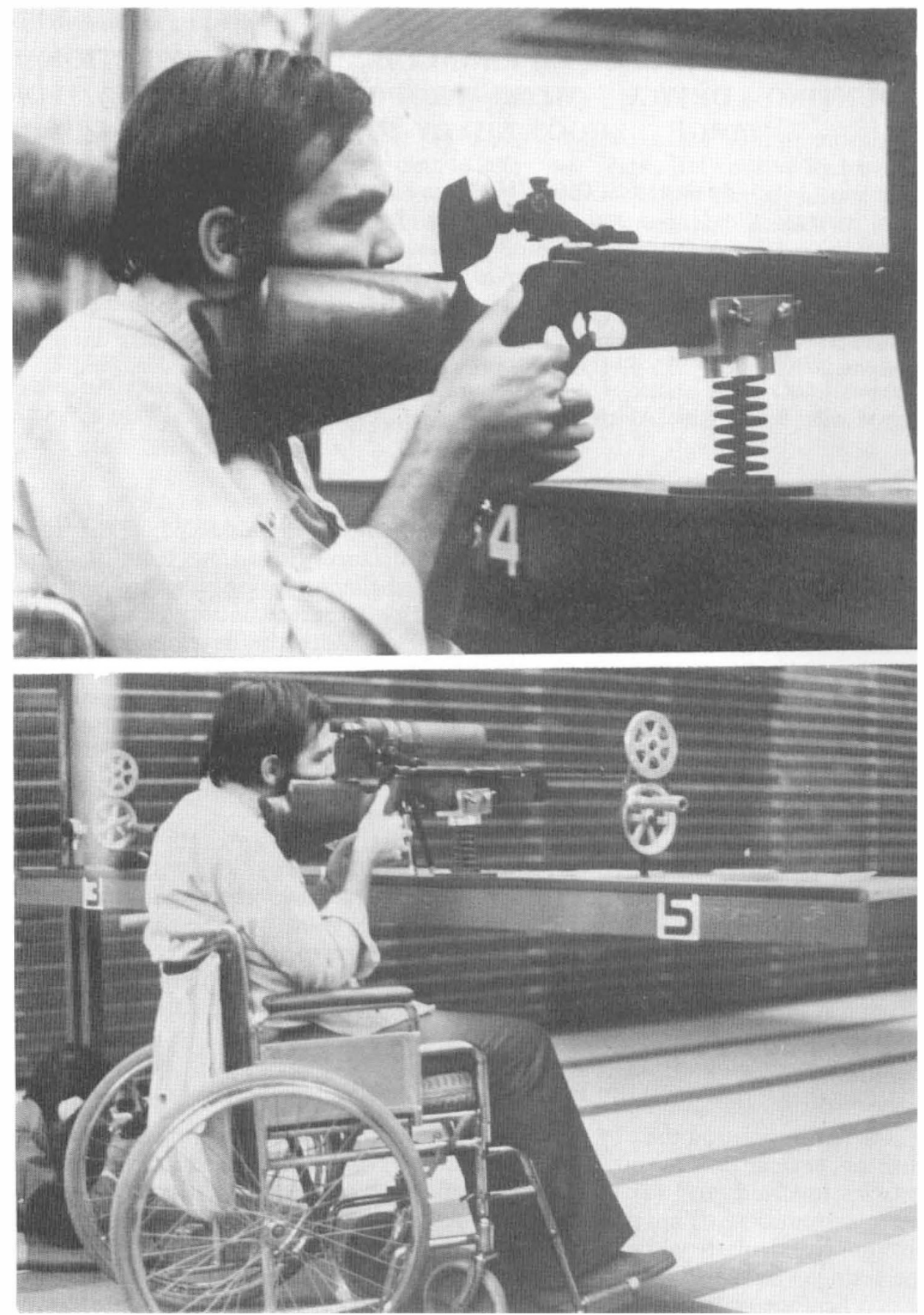

FIG. 
function below the level of their neurological lesion obviously cannot shoot in the upright position, except those with cauda equina syndrome or with central cord lesion. Considering the above observation, the only possible conclusion is that most persons with spinal cord injury will shoot while seated. The patient with cauda equina or central cord lesion can shoot from any position. This group will be divided into three classes:

I. Persons with lesions above and including Tro (corresponding to class 3 in ISMGC regulations) will shoot seated and leaning against the back of the wheelchair. They will also be allowed to use straps to stabilise the trunk against the wheelchair. This special concession will compensate this group for their difficulties in maintaining their balance while seated.

2. Persons with lesions from Tio to and including L3 (class 4 in ISMGC regulations) will shoot seated with optional leaning, or lying down.

3. Persons with lesions below L3 (class 5 and onward) will shoot seated (without leaning), standing or lying down.

Shooters with incomplete lesions must be considered thoroughly according to their individual disabilities.

\section{Lower Extremity Amputees}

The prosthesis compensates for the loss of movement and tactile sensation. In the case of bilateral amputation the condition above described is of course more acute, and in these cases even the seated position is not entirely stable. The amputee group will be divided into three classes:

I. Bilateral above knee amputation.

2. Bilateral amputation with one leg above knee and one leg below knee.

3. Amputation of one leg above knee and severe injury of the other leg.

Class I (A-6) will shoot seated and leaning against the chair. Class 2 (bilateral below knee amputation) will shoot seated without leaning backwards. Class 3 (unilateral amputees) will shoot standing up, but will be allowed to lean on a rectangular wooden stool, $70-90 \mathrm{~cm}$ high and $30 \times 50 \mathrm{~cm}$ wide. All other disabilities and mixed lesions will be examined by a committee of physicians and will be classified according to their findings.

\section{SUMMARY}

A new mounting and aiming device for rifle target shooting by the disabled is presented. We feel it will make one more sport suitable for the handicapped.

\section{RÉSUMÉ}

Un nouveau dispositif de support et de visée pour le tir au fusil par les handicapés est présenté. Nous estimons qu'il rendra un sport de plus accessible aux invalides.

\section{ZUSAMMENFASSUNG}

Es wird eine neue Stütz- und Zielvorrichtung für Gewehrschiessen durch Behinderte vorgestellt. Wir sind der Meinung, sie wird das Ausüben eines zusätzlichen Sports durch Invaliden ermöglichen. 